\title{
Uma e muitas: A representação da personagem feminina em Algum Lugar, de Paloma \\ Vidal
}

Joyce Luciane Correia Muzi ${ }^{1}$

Lúcia Osana Zolin²

Uma parte de mim é todo mundo: outra parte é ninguém: fundo sem fundo. Uma parte de mim é multidão: outra parte estranheza e solidão. Uma parte de mim pesa, pondera: outra parte delira. Uma parte de mim almoça e janta: outra parte se espanta.

Uma parte de mim é permanente: outra parte se sabe de repente. Uma parte de mim é só vertigem: outra parte, linguagem. Traduzir-se uma parte na outra parte - que é uma questão de vida ou morte será arte? (“Traduzir-se" de Ferreira Gullar)

Algum lugar (2009), romance de Paloma Vidal, escritora argentina naturalizada brasileira, foi escrito e ambientado no século XXI, de modo a inserir-se no contexto da pós-modernidade; no campo das artes, trata-se do pós-modernismo, segundo Terry

\footnotetext{
${ }^{1}$ Instituto Federal do Paraná; Universidade Estadual de Maringá.

${ }^{2}$ Docente do Programa de Pós-graduação em Letras da Universidade Estadual de Maringá.
} 
Eagleton, "movimento de pensamento contemporâneo que rejeita totalidades, valores universais, grandes narrativas históricas, sólidos fundamentos para a existência humana e a possibilidade de conhecimento objetivo" (2005, p. 27). Trata-se, portanto, de um conceito ideológico amplo, alicerçado na infraestrutura industrial e econômica ocidental e na globalização.

Interessam-nos as transformações dela decorrentes, pois estas repercutiram na produção dos artefatos culturais, em especial, na literatura, que passou a enfatizar a heterogeneidade, a diferença, a fragmentação, a indeterminação, sempre desconfiando dos discursos universais e totalizantes, pondo em xeque questões relacionadas a cânones oficiais e a estratégias narrativas inscritas na tradição literária. Escrever um romance nesse contexto implica não apenas criar um enredo, definir personagens, optar por esse ou aquele foco narrativo, tempo, espaço, dentro de um determinado contexto histórico e político, mas criar possibilidades de se discutir as diferenças, de tentar fazer coerentes as fragmentações, de se posicionar contra os padrões universais: "não temos mais as narrativas fechadas, de sentido completo" (Fernandes, 2009, p. 303).

E se tudo passa a ser questionado, questiona-se fundamentalmente a questão das identidades, já não mais tratadas no singular, uma vez que "sofrem" a ação dessas transformações. Há que se tentar entender de que maneira estas identidades são representadas em romances contemporâneos.

A narradora-protagonista de Algum lugar (2009), cujo nome o/a leitor/a não tem acesso, é uma praticante da chamada escrita do eu. Ela narra a respeito de si própria, de suas experiências e, sobretudo, a respeito das coisas que a atormentam. Esse exercício de tentar se conhecer é feito por meio da palavra escrita, que para Libanori (2011) é um instrumento para tentar entender as próprias experiências, por meio da reflexão. Nesse sentido, mais do que simplesmente narrar, sua intenção é indagar sobre seu modo de 
estar no mundo, sobre suas tentativas de criar sua(s) própria(s) identidade(s), por meio de um ponto de vista subjetivo.

Regina Dalcastagnè, no artigo intitulado "Vivendo a ilusão biográfica. A personagem e o tempo na narrativa brasileira contemporânea" (2005), chama atenção para o fato de que comumente na narrativa brasileira contemporânea são criados personagens que precisam organizar um passado, objetivando "dar um sentido ao presente, mesmo que esse sentido não passe de uma farsa" (Dalcastagnè, 2005, p. 116).

A personagem do romance em questão se encontra nessa busca de compreensão do presente a partir de seu passado. O livro foi escrito em forma de diário, o que significa que a escrita se dá à medida que os fatos vão acontecendo. É bom lembrar que o diário evoca um passado, mas um passado recente, justamente para se evitar o esquecimento ou a inexatidão dos fatos. E, ainda que as datas, marca característica do gênero, não estejam presentes, é possível identificar a presença do cotidiano, a narração centrada no vivido e a apresentação de fatos em ordem sucessiva. No entanto, intercalam-se na narrativa alguns poucos momentos de flashbacks, constituindo fator importante se considerarmos que os registros diários vão se somar às reminiscências na tarefa de delinear e/ou compreender sua(s) identidade(s).

Segundo Sheila Maciel (2004), o diário enquanto gênero confessional é uma das formas mais consolidadas de escrita de si, no entanto, durante muito tempo foi considerado gênero menor devido a seu caráter, em princípio, não ficcional. Este caráter não impede que encontremos diversas obras dentro do universo confessional puramente ficcionais, cuja forma autobiográfica consiste em um recurso a mais dentro da aventura da linguagem.

Se historicamente os gêneros confessionais eram considerados pela crítica como "menores", quando comparados às "altas literaturas", e se foram as mulheres quem 
mais deles se ocuparam, é possível pensar a escolha feita por Paloma Vidal pelo gênero como uma estratégia subversiva. O que fica em evidência aí é o caráter intimista do diário, além de sua relação com a própria condição humana, permitindo que ele se junte ao rol das estratégias narrativas tipicamente pós-modernas, como são, por exemplo, a paródia, a reescrita e a metanarrativa. Nossa hipótese é a de que esta escolha da autora aponta para uma busca por subverter os valores estéticos e ideológicos tradicionais, contribuindo para a inauguração de novos valores marcados pela contemporaneidade, ou pela chamada pós-modernidade.

O esforço da narradora-personagem é de, por meio da palavra escrita, estabelecer um efeito de continuidade aos fatos e sentimentos que muitas vezes são díspares. Por isso é tão importante a forma: utilizar-se da estrutura de um diário para tentar organizar um conjunto de fatos e memórias a respeito de si e de seu entorno, é uma tentativa de se compreender.

Trata-se, portanto, de lançar mão da estrutura do diário como estratégia de subversão estético-ideológica, à qual se somam outras práticas igualmente subversivas, típicas da pós-modernidade, como é o caso da mistura de vozes que aí se apresenta: mesmo quando relemos os parágrafos ou trechos, fica difícil identificar quem é que fala.

Do ponto de vista da forma, a alternância de vozes é marcada por blocos de texto e espaços vazios, estratégia que Fernandes, citando McHalle (1994), identifica como típica de textos pós-modernos: “Os textos pós-modernistas são tipicamente espaçados, literal e figurativamente. Capítulos extremamente curtos, ou parágrafos curtos separados por largas faixas de espaço em branco tornaram-se a norma" (Fernandes, 2009, p. 303).

As vozes se alternam entre primeira e terceira pessoas, exigindo do/a leitor/a um esforço que o/a leva a considerar essa mescla de vozes como reflexo da confusão interior 
da personagem, um típico sujeito pós-moderno, no dizer de Stuart Hall, “composto não de uma única, mas de várias identidades, algumas vezes contraditórias ou não resolvidas" (2011, p. 12).

A questão da identidade perpassa todo o romance, de tal modo que as múltiplas identidades que a narradora vai assumindo no decorrer de sua trajetória são tomadas, no conjunto, como motivos de angústia. Ela é mulher, brasileira, estudante/pesquisadora, professora, namorada/esposa, filha, irmã, imigrante, tudo concorrendo para sua construção enquanto sujeito descentrado, em crise no mundo contemporâneo, de acordo com a classificação de Hall (2011).

Não obstante a representação feminina que daí se abstrai ser consideravelmente diferente das tradicionais imagens de mulher que povoam a literatura, há que se considerar o fato de ser a maternidade, um atributo feminino considerado essencialista, que irá lhe conferir certa organização identitária. Ainda que sob suspeita, vemos a personagem aceitar uma identidade que prevalecerá sobre qualquer outra, em uma espécie de imposição biológica: seu corpo a "condenou" à maternidade. Paradoxalmente, "ser" mãe implicará para a narradora encontrar o caminho por onde ela escapa e, ao escapar, compreende as outras representações que desempenhou, com as quais ela lutou durante toda sua vida. Suas identidades múltiplas, portanto, serão suplantadas pelo desempenho do papel de mãe, e a partir desse momento ela buscará atender, não sem questionar, o que se espera socialmente de uma mãe: no mínimo, alguma responsabilidade pela vida daquele que gerou.

Até que chegasse a esse equilíbrio identitário, ao final de sua trajetória, a personagem percorrerá um caminho que pode ser chamado, na terminologia de Hall (2011), de "processo de identificação". Para o teórico, processo é problemático justamente porque as identidades entraram em colapso; o sujeito pós-moderno, 
“conceptualizado como não tendo uma identidade fixa, essencial ou permanente" (Hall, 2011, p. 13), é um ser em crise.

O estudioso explica que, no âmbito do senso comum, o conceito de identificação tem a ver com o "reconhecimento de alguma origem comum, ou de características que são partilhadas com outros grupos ou pessoas, ou ainda a partir de um mesmo ideal" (Hall, 2000, p. 106). Numa abordagem discursiva, todavia, a identificação é um processo e como tal pode não ter fim e pode não acontecer. Há a ideia de não fusão, uma vez que o processo não anula as diferenças. Nas palavras de Hall (2000), identificação implica um processo de articulação, uma "suturação", em que ora há uma sobredeterminação, ora uma falta, nunca um ajuste completo. Identificação, portanto, pressupõe uma política de exclusão, já que ao se identificar com algo ou alguém se instaura uma dicotomia, em que outros ("algo" ou "alguém") ficarão de fora. Daí o conceito de identidade:

Utilizo o termo "identidade" para significar o ponto de encontro, o ponto de sutura, entre, por um lado, os discursos e as práticas que tentam nos "interpelar", nos falar ou convocar para que assumamos nossos lugares como os sujeitos sociais de discursos particulares e, por outro lado, os processos que produzem subjetividades, que nos constroem como sujeitos aos quais se pode "falar". As identidades são, pois, pontos de apego temporário às posições-de-sujeito que as práticas discursivas constroem para nós. [...] as identidades são as posições que o sujeito é obrigado a assumir, embora "sabendo", sempre, que elas são representações, que a representação é sempre construída ao longo de 
uma "falta", ao longo de uma divisão, a partir do lugar do Outro... (Hall, 2000, p. 111-112).

Nesse sentido, Hall (2000) afirma, baseado em Foucault, que o sujeito é "convocado" a assumir uma "posição-sujeito" e permanece suturado a ela e, como já dito anteriormente, esta suturação ou articulação permite que falemos de identificação. Além disso, também tem fundamental importância a relação com o outro, ou com aquilo que lhe falta, ainda que o "que lhe falta seja um outro silenciado e inarticulado" (p. 110).

Ao longo da narrativa, esta não fixidez das identidades a perturbam, por isso suas inúmeras tentativas de atender às expectativas de seu entorno. Desde o início do romance, é possível perceber a necessidade que a personagem tem de se identificar com as outras pessoas. São inúmeras as tentativas de satisfazer o outro: marido, mãe, irmão, colegas, filho. Nota-se uma dependência permanente, porque ela não é capaz de tomar decisões, ficando sempre à espera que as escolhas sejam feitas pelos outros. Frustrada, ela encontrará na maternidade uma nova oportunidade, uma vez que ela agora se empenhará para atender a uma expectativa que ela supostamente escolheu.

Podemos notar dois núcleos de pessoas com quem a personagem se relaciona e busca identificar-se: um familiar e outro social. M é o marido/namorado que viaja para viver com ela em Los Angeles. Da relação entre os dois, é possível dizer que há uma dependência dela em relação a ele; seu medo, expresso durante toda a narrativa, é de perdê-lo, momentânea ou permanentemente.

Da parte dele, a relação não se dá da mesma maneira; ele consegue estabelecer uma rotina que a exclui, o que inclusive permite a ele decidir voltar antes dela para o Brasil; ao se ver sozinha, a narradora se fecha sobre si mesma, interrompendo as tentativas de se identificar com o espaço e com as pessoas a seu redor.

Brasiliana - Journal for Brazilian Studies. Vol. 3, n.1 (Jul. 2014). ISSN 2245-4373. 
O que teria motivado a mudança do casal para os EUA foi o desejo dela de fazer o doutorado. Entretanto, ao longo da narrativa essa motivação primeira vai sendo descartada à medida que ela não se sente capaz de fazê-lo e que vão surgindo questionamos acerca do fato de ser esse desejo realmente seu: "O que me fez pensar que conseguiria escrever uma tese? A ideia me parece cada vez mais distante. É como se tivesse sido em outra vida" (Vidal, 2009, p. 108). O objetivo "viajar para outro país para fazer uma tese" foi alcançado, ainda que a tese não tivesse sido concluída, e, nesse caso, permanece a pergunta: de quem de fato era o desejo?

Embora ela assuma que a última decisão que tomou "foi a de viajar para Los Angeles" (Vidal, 2009, p. 166), a dúvida do/a leitor/a permanece, pois sua atitude diante da possibilidade de fazer a tese era quase sempre de inércia; do mesmo modo que era a inércia que a fazia agir de forma indiferente quando da possibilidade de aproximação ou envolvimento com alguém.

Além de $\mathrm{M}$, há a mãe, o irmão e o pai, que quase nunca é citado, o que aponta para a hipótese de que entre eles não haja envolvimento afetivo. Sabemos da sua dificuldade de relacionamento com a mãe, motivada pela imposição dos valores da cultura argentina dela, quando, por exemplo, obriga a filha a falar, desde pequena, o espanhol.

A partir desse núcleo familiar é possível perceber os múltiplos papéis que a personagem tem de desempenhar: para a mãe e o marido ela é a estudante exemplar e com um futuro brilhante pela frente, uma vez que tem a oportunidade de cursar seu doutorado em Los Angeles. Para a mãe é a profissional competente a quem faz questão de ajudar quando de suas dificuldades relacionadas ao ensino da língua espanhola (sua língua materna). Mesmo à distância, também faz questão de orientá-la sobre que lugares conhecer/visitar em Los Angeles. 
Para M, ela é a companheira ideal, que sabe calar quando necessário, e está ao seu lado sempre que precisa. Para o irmão, ela é aquela que terá as oportunidades que ele não poderá ter, devido a uma doença que não sabemos se o matou ou o deixou incapacitado.

Vemos durante a leitura de seus registros que estas relações são a base para as impressões a respeito de si mesma. Isso aponta para o cumprimento ou para a ocupação de posições-sujeito específicas: a personagem segue a previsibilidade daquilo que dela se espera, ou seja, deixa-se levar por aquilo que antecipadamente se tem como ideal de filha, estudante, irmã, esposa.

Da relação com um núcleo que poderíamos chamar de social, uma colega se destaca: Luci, uma coreana que também está estudando em Los Angeles. Elas se aproximam, pois se identificam como duas estrangeiras estudando literatura em outro país. Luci representa um reflexo de si própria: "Pela primeira vez, diante desse espelho novo, começo a achar que estou no caminho certo, que estar ali faz sentido, que minhas leituras caminham para algum lugar" (Vidal, 2009, p. 55). É uma forma de dizer pra si que vai conseguir realizar a tese e viver nesse país desconhecido.

Ainda que de personalidades e culturas completamente diferentes, Luci se parece com ela, tornando-se uma das únicas possibilidades de identificação. E as diferenças visíveis entre elas não impedem que a coreana invista e se esforce por essa amizade, porém somente ela se esforça. Partindo do fato de que têm mais diferenças do que semelhanças, a protagonista trata Luci de modo esquivo, o que lhe dificulta as investidas. Quando é cobrada, ela culpa a incapacidade linguística, já que em espanhol, a língua pela qual se comunicavam, não conseguia dizer o que sentia. Mas ao mesmo tempo lhe vem a dúvida: é um problema da língua ou um problema dela? 
Em um de seus encontros com Luci é possível notar uma contradição entre a necessidade de identificação da personagem e seu fechamento em si mesma, numa luta por não se deixar descobrir. Numa ocasião, Luci a leva a uma espécie de shopping a céu aberto:

Resolvo experimentar uma blusa. Luci olha para mim com desconfiança. Repreensão, mais precisamente. Tenho a sensação de ter atravessado uma fronteira invisível entre o que deve e não deve ser feito, mas do que poderia se tratar, se estamos numa loja, num shopping, aonde as pessoas vão para comprar coisas? Luci declara então que nunca comprou nada ali, que é tudo muito caro, e se fecha numa redoma. Eu gostaria então de perguntar o que costuma fazer nos seus passeios por The Grove, pois não parece ser um interesse antropológico o que a atrai [...]. Mas também me fecho e simplesmente deixo a blusa onde a encontrei (Vidal, 2009, p. 71).

É evidente que esse conflito a impede de agir naturalmente e é isso que acaba ficando para Luci: que o manter-se fechada é sinônimo de egoísmo. A aparente similaridade entre as duas, pelo fato de compartilharem de uma condição semelhante - serem estrangeiras inscritas numa cultura diversa, intencionando produzir um trabalho acadêmico e voltar para suas casas - não é suficiente para que estabeleçam uma relação sincera. Dessa relação, para a narradora, fica a culpa expressa no relato de um sonho, em que ambas estão de volta à casa de Luci, sentadas no sofá conversando. Nada da tensão anterior, nada de cobrança de Luci - somente duas amigas sentadas conversando. 
É clara a crise vivida pela personagem: se por um lado ela quer corresponder ao desejo do outro - quer ser desejada por M e por outros homens, quer estabelecer uma relação de amizade com alguém e agradar esse alguém -, por outro, ela não se empenha nessa empreitada; pelo contrário, se esconde das possíveis amigas, se fecha para $\mathrm{M} \mathrm{e}$ para o outro pretendente, se nega a desempenhar a função de professora de espanhol (algo que satisfazia sua mãe); tudo isso pode representar uma tentativa de se libertar e encontrar seu próprio desejo.

Algumas passagens, telegráficas, apontam para essa tentativa de se compreender: "Você queria realmente estar aqui?" (Vidal, 2009, p. 18); "Você acha que vamos conseguir ficar?" (VIDAL, 2009, p. 32); “O que você tinha imaginado?” (Vidal, 2009, p. 35). Ao escrever, a personagem é capaz de significar e mergulhar naquilo que pode parecer não ter lógica, mas que depois de organizado se torna um retrato daquilo que pretenderam que ela fosse; nas palavras de Hall (2000), das posições de sujeito que pretenderam que ela assumisse:

Você sonha que terminou a tese. Está com o texto na mão, um bloco retangular bastante grosso, encadernado com uma capa azul, que carrega debaixo do braço por um longo corredor mal iluminado. No final dele, duas portas de elevador, ambas fechadas. Uma delas se abre e aparece sua mãe. Está jovem, de cabelos compridos, idêntica a uma foto tirada no Chile, antes de seu nascimento, antes mesmo de se casar com o seu pai. ¡Conseguiste terminar a tiempo!, ela exclama. Você lhe mostra o bloco azul e ela pergunta: ¿sobre qué es? Sobre vos, você responde (Vidal, 2009, p. 59-60. Sonho 7). 
Nesse sonho relatado é possível perceber que a expectativa de agradar a mãe se converte em trauma. A contradição desse sonho está no fato dela ter terminado uma tese sobre a própria mãe.

Em alguns sonhos, que são um total de vinte e quatro ao longo da narrativa, ela se mostra muito mais segura e confiante do que na realidade é: “Está escuro e a rua está deserta, mas você não sente medo. [...] Você então decide descer pelos cabos do elevador para ver o que está acontecendo lá embaixo e o faz com uma habilidade surpreendente" (Vidal, 2009, p. 102. Sonho 15).

A relação com a mãe, aparentemente a mais difícil para a protagonista, perpassa toda a narrativa, atormentando-a em vários dos seus sonhos. É possível inferir que sua dificuldade em se encontrar, se entender e se identificar com as pessoas e os lugares que a circundam nasce tanto com a questão da linguagem, já que a "língua materna" 3 não atendia às suas expectativas identitárias, quanto com a questão da própria relação mãe e filha.

Nesse caso, é interessante pensarmos na trajetória da personagem. Diante de um vazio deixado por $\mathrm{M}$ e da sensação de não pertencer à cidade, outro conflito bastante presente, um pensamento lhe vem: poderia ter um filho. É quando retorna ao Brasil, a princípio para uma viagem de férias, que ela se descobre grávida. Já quase no final do livro, acontece o nascimento do filho, nomeado $\mathrm{C}$, o abandono da tese e seu reestabelecimento na cidade do Rio de Janeiro. Já separada de $M$, ela narra em poucas páginas algumas passagens dos primeiros anos de vida da criança.

Nesse momento, instaura-se uma nova etapa em que a personagem irá assumir uma nova identidade: a de mãe e de mulher separada. Como mãe, é notória a mudança

\footnotetext{
${ }^{3}$ Aqui "língua materna" está tomada em seu sentido literal; a língua da mãe, a espanhola, que a mãe imputara à filha como parte de sua identidade, a atormenta, na medida que ela não se sente à vontade se expressando por meio dela, tampouco se dizendo professora dessa língua.
}

Brasiliana - Journal for Brazilian Studies. Vol. 3, n.1 (Jul. 2014). ISSN 2245-4373. 
de perspectiva em relação a quem ela quer ser, ou quem ela é. A personagem agora está empenhada em colaborar para a constituição da(s) identidade(s) do filho.

É a partir das vontades do filho que ela agora se lança a novas relações com as pessoas. E isso tem a ver com a sua crise de identidades, uma vez que é possível perceber uma evolução, quase como uma solução encontrada. Ela desiste da tese, não tenta se reconciliar com Luci, volta para o Brasil, assume a condição de mãe e de docente de língua espanhola, reconcilia-se com sua mãe, separa-se de M: ainda que algumas dessas mudanças tenham sido traumáticas, esta é sua maneira de subverter aquilo que dela se espera. Depois de querer corresponder às expectativas, ela as contraria e faz algumas escolhas dentro dos limites do que se espera dela socialmente.

Ao escolher voltar para o Brasil ela deixa para trás suas tentativas frustradas de se identificar com as pessoas que encontrara, muitas nas mesmas condições que ela. Deixa também no passado a expectativa de se tornar doutora.

Ao se tornar mãe, mesmo antes de o bebê nascer, ela compreende o que isso significava: "Meu corpo é de interesse de toda a família" (Vidal, 2009, p. 137). Agora ela não é mais a filha, estudante, pesquisadora, professora etc. - a maternidade a transformara num corpo que interessava a todos.

No entanto, alguma angústia ainda permanece por se perceber distante da expectativa social. Grávida ela quer mais um tempo antes do menino nascer; depois de nascido ela percebe que o pai tem mais confiança e segurança do que ela. $\mathrm{O}$ fato de ser mulher não lhe garantiu que esses sentimentos surgissem, contrariando uma expectativa social - o que se espera é que uma mãe tenha despertada uma confiança "natural" quando tome seu/sua filho/a nos braços, fazendo-lhe capaz de decifrar e distinguir os choros. Ela até se esforça, mas assume sua dificuldade em corresponder a mais essa expectativa:

Brasiliana - Journal for Brazilian Studies. Vol. 3, n.1 (Jul. 2014). ISSN 2245-4373. 
Os livros falam de aprendizagem, mas penso que isso pode levar anos e não sei como sobreviver às próximas horas. Uma amiga me recomenda um mantra: eu vou conseguir. Sentada no chão do chuveiro, único lugar em que me sinto a salvo, repito "eu vou conseguir", "eu vou conseguir", “eu vou conseguir" e, gradualmente, como se minha língua já não me pertencesse, a pequena frase vai se transformando numa pergunta que me aterra: "eu vou conseguir?" (Vidal, 2009, p. 142).

Sua dificuldade em acreditar que desempenhará bem mais esse papel atribuído impele a personagem a fazer seu filho independente. Essa decisão entra em contradição quando ela narra o dia em que esqueceu a janela aberta e um temporal encharcou a criança, deixando-a doente. Sua ânsia por ensinar o filho a ser independente deu lugar à culpa. Mas C finalmente aprende e isso, ao mesmo tempo que a desespera, uma vez que como mãe acredita que deva haver um vínculo de confiança e dependência, a conforta: "Nos últimos meses, vem desenvolvendo a capacidade de estar ao meu lado sem demandar minha atenção" (Vidal, 2009, p. 159). Agora o filho aprende a ser independente e é o filho que toma as decisões.

O menino que, como a mãe, será exposto a duas culturas diferentes - a brasileira e a argentina, por necessidade da avó materna -, aprendia a transitar entre línguas e opiniões diferentes; e aprendia desde muito cedo que isso não é aquilo, mas que as coisas podem se parecer.

A vinda do filho a libertou de posições que lhe faziam mal, mas também the trouxe uma nova forma de se enxergar - seu corpo mudou, sua vida se transformou; não tinha mais M para tomar as decisões, não tinha mais a tese, não precisava mais viver em 
outro país, um dos aspectos que contribuíram para que ela refletisse sobre as múltiplas identidades que lhe foram impostas durante toda sua vida.

O sujeito pós-moderno, ainda que fragmentado, apresenta uma angústia por se encontrar e se identificar de modo a juntar as partes para se constituir como sujeito. É uma busca por se traduzir. Traduzir é transferir, mas é também ser reflexo ou a imagem de, representar, simbolizar. A personagem de Algum lugar está numa permanente busca por encontrar suas partes, dentro e fora de si mesma, de maneira a fazer parte de algo maior.

Tal como expresso pelo eu-lírico do poema que serve de epígrafe para este texto, somos partes formando um todo que às vezes não corresponde ao que dele se espera.

Isso é o que se revela em todo o romance; por estar pautado sobre a questão pósmoderna da crise de identidade, todos os fatos - a tese não terminada, a necessidade de identificação/relação com as pessoas, as múltiplas identidades, o ser mãe - angustiam a personagem, mas, mais do que isso, contribuem para que ela olhe para seu passado e construa o presente. Hall atesta a legitimidade desse esforço:

...não o assim chamado "retorno às raízes", mas uma negociação com nossas "rotas". Elas surgem da narrativização do eu, mas a natureza necessariamente ficcional desse processo não diminui, de forma alguma, sua eficácia discursiva, material ou política, mesmo que a sensação de pertencimento, ou seja, a "suturação à história" por meio da qual as identidades surgem, esteja, em parte, no imaginário (assim como no simbólico) e, portanto, sempre, em parte, construída na fantasia ou, ao menos, no interior de um campo fantasmático (2011, p. 109). 
A personagem escreve para se constituir como sujeito, e ao negociar com suas "rotas" ela se compreende dentro da imensa rede em que está inserida, na maioria das vezes contra sua vontade. História, linguagem e cultura produzem aquilo que devemos nos tornar, por isso a relevância dessa narrativa que problematiza as identidades cada vez mais fraturadas e plurais. E se "elas não são, nunca, singulares, mas multiplamente construídas ao longo de discursos, práticas e posições que podem se cruzar ou ser antagônicos" (Hall, 2011, p. 108), Paloma Vidal bem se apercebe disso e representa no universo ficcional.

Em Algum lugar, o centro da narrativa segue sendo a personagem feminina, e as várias relações que estabelece com seu entorno, como comumente acontece na literatura de autoria feminina ${ }^{4}$, porém esta personagem principal agora assume sua condição pósmoderna - é um sujeito descentrado (Hall, 2011), ou seja, sua identidade é formada não apenas pela identidade da mulher se debatendo com os entraves do patriarcalismo, mas por várias: ela é agora a professora, a estudante, a pesquisadora, a namorada, a esposa, a filha, a irmã, a imigrante. Nesse sentido, a autora aponta para uma mudança ao representar um indivíduo em crise no mundo contemporâneo, o que significa pôr luz em aspectos múltiplos como o do pertencimento nacional, da classe social, da raça, da etnia, da orientação sexual, além do gênero. Por outro lado, é a partir do ser mulher que a trajetória da personagem aponta para uma permanência, já que o ser mãe prevalecerá sobre qualquer outra marca identitária, ainda que ela se dê conta de que tampouco conseguirá atender a esta expectativa.

E, se suas questões identitárias parecem se resolver por meio da maternidade, não nos parece que a escritora esteja se remetendo a uma solução essencialista para as

\footnotetext{
${ }^{4}$ Haja vista, além das obras da própria Paloma Vidal, as obras de autoras contemporâneas como Elvira Vigna, Adriana Lunardi, Ana Maria Machado, dentre outras autoras que centram seus enredos em personagens mulheres e as relações que estas estabelecem com o mundo.
}

Brasiliana - Journal for Brazilian Studies. Vol. 3, n.1 (Jul. 2014). ISSN 2245-4373. 
angústias femininas; antes nos parece se tratar de um projeto seu que, ao se materializar, abre possibilidades para outras realizações.

A protagonista deste romance, que foi finalista do Prêmio São Paulo de Literatura e semifinalista do Prêmio Portugal Telecom em 2010, tem um ponto de partida - a tentativa de se compreender a partir dos registros do passado, e tem um ponto de chegada - possibilitar um mergulho numa condição individual (que não é só feminina) e coletiva ao mesmo tempo: a busca constante por autoconhecimento, por se aproximar dos/as outros/as, de algum lugar, ou de qualquer lugar.

\section{Referências}

Dalcastagné, Regina. Vivendo a ilusão biográfica. A personagem e o tempo na narratva brasileira contemporânea. Literatura e Sociedade, São Paulo, n. 8, p. 112-125, 2005.

Fernandes, Giséle M. O pós-modernismo. In: Bonnici, Thomas; Zolin, Lúcia O. (Orgs.). Teoria literária: abordagens históricas e tendências contemporâneas. 3. ed. rev. e ampl. Maringá: Eduem, 2009. p. 301-315.

Eagleton, Terry. Depois da teoria: um olhar sobre os estudos culturais e o pósmodernismo. Tradução de Maria Lucia Oliveira. Rio de Janeiro: Civilização Brasileira, 2005.

Foucault, M. A hermenêutica do sujeito. 2. ed. São Paulo: Martins Fontes, 2006.

Hall, Stuart. A identidade cultural na pós-modernidade. 11. ed., 1. reimp. Tradução de Tomaz T. da Silva e Guacira Lopes Louro. Rio de Janeiro: DP\&A, 2011.

- Quem precisa da identidade? In: Silva, Tomaz Tadeu (Org.). Identidade $e$ diferença: a perspectiva dos estudos culturais.. Petrópolis: Vozes, 2000. p. 103-133. 
Libanori, Evely V. Escrita do eu e construção de identidade. (Material usado em sala de aula).s.p.

Maciel, Sheila D. A literatura e os gêneros confessionais. 2007. Disponível em: http://www.cptl.ufms.br/pgletras/docentes/sheila/A\%20Literatura $\% 20 \mathrm{e} \% 20 \mathrm{os} \% 20 \mathrm{~g} \% \mathrm{EA}$ neros\%20confessionais.pdf Acesso em: 12 jan. 2012.

Vidal, Paloma. Algum lugar. Rio de Janeiro: 7Letras, 2009. 